\title{
STUDI ASUHAN KEBIDANAN KOMPREHENSIF DI PRAKTIK MANDIRI BIDAN YANG TERSTANDARISASI APN
}

\author{
Siti Noorbaya 1)Herni Johan 2) Dian Puspita Reni3) \\ 1)2)3)AkademiKebidananMutiaraMahakam, Samarinda,Indonesia \\ E-mail: sitinoorbaya@akbidmm.ac.id \\ E-mail : hernijohan@akbidmm.ac.id \\ E-mail : dianpuspitareni@akbidmm.ac.id
}

\begin{abstract}
The number of MMR is very high in the world. In 2016, more than 216 per 100,000 live births of women die every day due to complications of pregnancy and child birth, recorded 800 women die every day. Based on data from the Ministry of Health, the number of MMR in Indonesia in 2016 is 305 maternal deaths per 100,000 live births, while the AKB is 22.23 per 1,000 live births. MMRin East Kalimantan is still high as many as 137 people from the number of live birth as many as 69.372 people and as many as 7 babies IMR. This becomes an irony because to achieve the target of SDG, s up to 2030 is reducing MMRbelow 70 per 100,000 live births and by 2030 ending preventable infant and toddler deaths. For that role, midwife as health worker does continuity of care which has been standardized APN able to decrease MMR and IMR. This study aims to describe the implementation of comprehensive midwifery care in Standardized Midwife Practice APN Samarinda. The method used is descriptive qualitative with case study approach. The subjects of the study were trimester pregnant women III. The results of the study of comprehensive care (Continuity of Care) given starting from pregnancy, delivery, newborn, childbirth, neonate until the family planning of normal walking there is no data leading to emergency or pathological and there is no gap between theory and practice. From the results of the study it can be concluded that comprehensive care given to patients starting from pregnancy, delivery, newborn, childbirth, neonates until care KB get physiological results and can prevent emergency maternal and neonatal emergency
\end{abstract}

Keywords: Midwifery Care, Comprehensive, APN'S Standard-Based

\begin{abstract}
Abstrak
Jumlah AKI sangat tinggi di dunia, pada tahun 2016 lebih dari 216 per 100.000 kelahiran hidup perempuan meninggal setiap hari akibat komplikasi kehamilan dan kelahiran anak, tercatat 800 perempuan meninggal setiap harinya. Berdasarkan data Kementrian Kesehatan jumlah AKI di Indonesia pada tahun 2016 yaitu 305 kematian ibu per 100.000 kelahiran hidup, sedangkan AKB sebesar 22,23 per 1.000 kelahiran hidup. AKI di Kaltim masih tinggi sebanyak 137 orang dari jumlah hidup lahir sebanyak 69,372 orang dan AKB sebanyak 7 bayi. Hal ini menjadi ironi karena untuk mencapai target SDG,s hingga tahun 2030 adalah mengurangi AKI dibawah 70 per 100.000 kelahiran hidup dan pada 2030 mengakhiri kematian bayi dan balita yang dapat dicegah. Untuk itu peran bidan sebagai tenaga kesehatan melakukan continuity of care yang sudah terstandarisasi APN mampu menurunkan AKI dan AKB. Penelitian ini bertujuan mendiskripsikan pelaksanaan asuhan kebidanan komprehensif di Praktik
\end{abstract}


Bidan Mandiri yang terstandarisasi APN Samarinda. Metode yang digunakan yaitu diskriptif kualitatif dengan pendekatan studi kasus. Subyek penelitian adalah ibu hamil trimester III. Hasil penelitian yaitu asuhan komprehensif (Continuity of Care) yang diberikan mulai dari kehamilan, persalinan, bayi baru lahir, nifas, neonatus sampai dengan asuhan KB berjalan normal tidak ada data yang mengarah kegawatdaruratan ataupun patologis dan tidak ada kesenjangan antara teori dengan praktik. Dari hasil penelitian dapat disimpulkan bahwa asuhan komprehensif yang diberikan kepada pasien mulai dari kehamilan, persalinan, bayi baru lahir, nifas, neonatus sampai dengan asuhan KB mendapatkan hasil fisiologis dan dapat mencegah kegawatdaruratan maternal dan neonatal.

Kata Kunci : Asuhan Kebidanan, Komprehensif, Terstandarisari APN

\section{PENDAHULUAN}

Masalah kesehatan dan mortalitas sangat erat hubungannya dengan Angka Kematian Ibu (AKI) atau lebih dikenal maternal mortality. Kematian maternal adalah kematian perempuan pada saat hamil atau selama 42 hari sejak terminasi kehamilan tanpa memandang lama dan tempat persalinan, yang disebabkan karena kehamilannya atau pengelolaannya.

Jumlah AKI sangat tinggi di dunia, pada tahun 2016 lebih dari 216 per 100.000 kelahiran hidup perempuan meninggal setiap hari akibat komplikasi kehamilan dan kelahiran anak, tercatat 800 perempuan meninggal setiap harinya. Berdasarkan data Kementrian Kesehatan jumlah AKI di Indonesia pada tahun 2016 yaitu 305 kematian ibu per 100.000 kelahiran hidup, sedangkan AKB sebesar 22,23 per 1.000 kelahiran hidup. AKI di Kaltim masih tinggi sebanyak 137 orang dari jumlah hidup lahir sebanyak 69,372 orang dan AKB sebanyak 7 bayi.

Continuity of Care (CoC) adalah pelayanan yang dicapai ketika terjalin hubungan yang terus menerus antara klien dan bidan. Asuhan yang berkelanjutan berkaitan dengan kualitas pelayanan dari waktu kewaktu yang membutuhkan hubungan terus menerus antara klien dengan tenaga kesehatan yang profesional, tentunya dengan tenaga bidan yang telah memiliki sertifikat APN (Asuhan Persalinan Normal), untuk mencapai target SDG,s hingga tahun 2030 adalah mengurangi AKI dibawah 70 per 100.000 kelahiran hidup dan pada 2030 mengakhiri kematian bayi dan balita yang dapat dicegah. Maka dari itu peran bidan sebagai tenaga kesehatan melakukan continuity of care dan sudah terstandarisasi APN mampu menurunkan AKI dan AKB.

$$
\text { Penelitian ini bertujuan }
$$

mendiskripsikan pelaksanaan asuhan kebidanan komprehensif di Praktik Bidan Mandiri yang terstandarisasi APN Samarinda. Secara khusus untuk mengetahui gambaran pelaksananaan asuhan kebidanan kehamilan, persalinan, bayi baru lahir, nifas, neonatus sampai dengan konseling $\mathrm{KB}$ menggunakan pola pikir ilmiah melalui pendekatan tujuah langkah varney, Metode yang digunakan yaitu diskriptif kualitatif dengan pendekatan studi kasus. 


\section{METODE PENELITIAN}

Metode yang digunakan yaitu diskriptif kualitatif dengan pendekatan studi kasus. Subyek penelitian adalah ibu hamil trimester IIIdengan atau tanpa faktor resiko, ibu bersalin, bayi baru lahir, ibu nifas,neonatus serta calon akseptor KB. Adapun teknik pengumpulan data yang akan digunakan adalah data primer dan data sekunder. Data primer meliputi wawancara, observasi dan pemeriksaan fisik serta asuhan sedangkan data sekunder meliputi menggali data pada kohort ibu dilahan praktik, data dari buku KIA, kemudian data yang digunakan pada penelitian ini mengubah data hasil penelitian menjadi suatu informasi yang digunakan untuk mengambil kesimpulan yang didokumentasikan kedalam bentuk SOAP.

Dalam melakukan asuhan kebidanan komprehensif ini, peneliti menggunakan format pengkajian dan checklist, lembar observasi dan partograf, leaflet serta alat-alat instrumen yang digunakan yaitu ANC kit, Partus kit, serta alat untuk pemeriksaan bayi baru lahir.

\section{HASIL DAN PEMBAHASAN}

Berdasarkan hasil pengumpulan data primer dan data sekunder pelaksanaan Asuhan Komprehensif di Praktik Bidan Mandiri yang Terstandarisasi APN Samarinda Tahun 2018.

Tabel 1.1 Distribusi Pelaksanaan Asuhan Kebidanan Kehamilan di Praktik Bidan Mandiri Samarinda Tahun 2018

\begin{tabular}{lll}
\hline $\begin{array}{l}\text { Asuhan } \\
\text { Kehamilan }\end{array}$ & $\begin{array}{l}\text { Implement } \\
\text { asi }\end{array}$ & Waktu \\
\hline ANC & Bidan telah & 09/03/18 \\
Kunjungan & $\begin{array}{l}\text { melaksnak } \\
\text { ke } 1\end{array}$ & an \\
& kunjungan & \\
& ANC & \\
ANC & Bidan telah $\quad 13 / 03 / 18$ \\
Kunjungan & melaksnak \\
ke 2 & an \\
& kunjungan & \\
& ANC \\
\hline
\end{tabular}

Berdasarkan tabel1diatas, didapatkan gambaran pelaksanaan asuhan kebidanan kehamilan yaitu sebanyak $2 \mathrm{x}$ (kali)ANC kunjungan ke 1 (09/03/18)dan ANC kunjungan ke 1 (13/03/18). Dengan melakukan pendokumentasian SOAP (Subyektif, Obyektif, Assesment dan Planning).

Tabel 1.2 Distribusi Pelaksanaan Asuhan Kebidanan Persalinan di Praktik Bidan Mandiri Samarinda Tahun 2018

\section{Asuhan Implementasi Waktu Persalina}

$\mathrm{n}$

\begin{tabular}{|c|c|c|c|}
\hline $\begin{array}{l}\text { Kala } \\
(13.10)\end{array}$ & 1 & $\begin{array}{l}\text { Bidan telah } \\
\text { melaksnakan } \\
\text { Asuhan kala I }\end{array}$ & $13 / 03 / 18$ \\
\hline $\begin{array}{l}\text { Kala } \\
(15.20)\end{array}$ & 2 & $\begin{array}{l}\text { Bidan telah } \\
\text { melaksnakan } \\
\text { Asuhan kala II }\end{array}$ & $13 / 03 / 18$ \\
\hline $\begin{array}{l}\text { Kala } \\
(15.37)\end{array}$ & 3 & $\begin{array}{l}\text { Bidan telah } \\
\text { melaksnakan } \\
\text { Asuhan kala } \\
\text { III }\end{array}$ & $13 / 03 / 18$ \\
\hline $\begin{array}{l}\text { Kala } \\
(15.50)\end{array}$ & 4 & $\begin{array}{l}\text { Bidan telah } \\
\text { melaksnakan } \\
\text { Asuhan kala } \\
\text { IV }\end{array}$ & $13 / 03 / 18$ \\
\hline
\end{tabular}


Berdasarkan tabel 2 diatas, didapatkan gambaran pelaksanaan asuhan kebidanan persalinan yaitu ada 4x tahapan Kala Persalinan meliputi Kala 1 pukul (13.10 wita) Kala 2 pukul (15.20 wita) Kala 3 pukul (15.37 wita) dan Kala 4 pukul (15.50 wita). Dengan melakukan pendokumentasian SOAP (Subyektif, Obyektif, Asessment, dan Planning).

Tabel 1.3 Distribusi Pelaksanaan Asuhan Kebidanan Bayi Baru Lahir di Praktik Bidan Mandiri Samarinda Tahun 2018

\begin{tabular}{clc}
\hline $\begin{array}{c}\text { Asuhan } \\
\text { BBL }\end{array}$ & Implementasi & Waktu \\
\hline BBL (0- & Bidan telah & $13 / 03 / 18$ \\
12 Jam) & melaksnakan & \\
& Asuhan BBL \\
\hline
\end{tabular}

Berdasarkan tabel 3 diatas, didapatkan gambaran pelaksanaan asuhan kebidanan Bayi Baru Lahir yaitu ada 1x yaitu asuhan pada saat bayi baru lahir. Dengan melakukan pendokumentasian SOAP (Subyektif, Obyektif,Assesment dan Planning).

Tabel 1.4 Distribusi Pelaksanaan Asuhan Kebidanan Nifas di Praktik Bidan Mandiri Samarinda Tahun 2018

\begin{tabular}{|c|c|c|}
\hline $\begin{array}{c}\text { Asuhan } \\
\text { Nifas }\end{array}$ & Implementasi & Waktu \\
\hline $\begin{array}{l}\text { KF } 1 \text { (6 } \\
\text { jam }-3 \text { hr) }\end{array}$ & $\begin{array}{l}\text { Bidan telah } \\
\text { melaksnakan } \\
\text { Kunjunga } \\
\text { Nifas I }\end{array}$ & $14 / 03 / 18$ \\
\hline $\begin{array}{l}\mathrm{KF} 2(4- \\
28 \mathrm{hr})\end{array}$ & $\begin{array}{l}\text { Bidan telah } \\
\text { melaksnakan }\end{array}$ & $18 / 03 / 18$ \\
\hline
\end{tabular}

\begin{tabular}{|c|c|c|c|}
\hline \multirow{6}{*}{$\begin{array}{l}\text { KF } \\
(29-42 \\
h r)\end{array}$} & & Kunjunga & \multirow{6}{*}{$20 / 03 / 18$} \\
\hline & & Nifas II & \\
\hline & 3 & Bidan telah & \\
\hline & & melaksnakan & \\
\hline & & Kunjunga & \\
\hline & & Nifas III & \\
\hline
\end{tabular}

Berdasarkan table 4 diatas, didapatkan gambaran pelaksanaan asuhan kebidanan Nifas yaitu ada 3x (kali) kunjungan yaitu KF 1 pada pukul (05.00 wita), KF 2 pada pukul (15.35 wita), KF 3 pada pukul (15.00 wita). Dengan melakukan pendokumentasian SOAP (Subyektif, Obyektif, Asessment, dan Planning).

Tabel 1.5 Distribusi Pelaksanaan Asuhan Kebidanan Neonatus di Praktik Bidan Mandiri Samarinda Tahun 2018

\begin{tabular}{|c|c|c|}
\hline $\begin{array}{l}\text { Asuhan } \\
\text { Neonatu } \\
\text { s }\end{array}$ & $\begin{array}{l}\text { Implementas } \\
\text { i }\end{array}$ & Waktu \\
\hline $\begin{array}{l}\text { KN } 1 \text { (6- } \\
42 \text { jam) }\end{array}$ & $\begin{array}{l}\text { Bidan telah } \\
\text { melaksnakan } \\
\text { Kunjunga } \\
\text { Neonatal I }\end{array}$ & $\begin{array}{l}14 / 03 / 1 \\
8\end{array}$ \\
\hline $\begin{array}{l}\text { KN } 2 \text { (3-7 } \\
\text { hr) }\end{array}$ & $\begin{array}{l}\text { Bidan telah } \\
\text { melaksnakan } \\
\text { Kunjunga } \\
\text { Neonatal II }\end{array}$ & $\begin{array}{l}18 / 03 / 1 \\
8\end{array}$ \\
\hline $\begin{array}{l}\mathrm{KN} 3(8- \\
28 \mathrm{hr})\end{array}$ & $\begin{array}{l}\text { Bidan telah } \\
\text { melaksnakan } \\
\text { Kunjunga } \\
\text { Neonatal III }\end{array}$ & $\begin{array}{l}27 / 03 / 1 \\
8\end{array}$ \\
\hline
\end{tabular}

Berdasarkan tabel 5 diatas, didapatkan gambaran pelaksanaan asuhan kebidanan Neonatus yaitu ada 3x (kali) kunjungan yaitu KN 1 pada pukul (08.00 wita), KF 2 pada pukul (15.10 wita), KF 3 pada pukul (15.00 wita). Dengan 
melakukan pendokumentasian SOAP (Subyektif, Obyektif, Asessment, dan Planning)

Tabel 1.6 Distribusi Pelaksanaan Asuhan Kebidanan Konseling KB di Praktik Bidan Mandiri Samarinda Tahun 2018

\begin{tabular}{lll}
\hline $\begin{array}{c}\text { Asuhan } \\
\text { KB }\end{array}$ & Implementasi & Waktu \\
\hline Asuhan & Bidan telah & 27/03/18 \\
Akseptor & melaksnakan & \\
KB & Asuhan & \\
& Keluarga & \\
& Berencana & \\
\hline
\end{tabular}

Berdasarkan tabel 3 diatas, didapatkan gambaran pelaksanaan asuhan kebidanan alat kontrasepsi yaitu ada $1 \mathrm{x}$ yaitu asuhan pada akseptor KB pukul (15.30 wita). Dengan melakukan pendokumentasian SOAP (Subyektif, Obyektif, Asessment, dan Planning).

Gambar 1.1 Distribusi pelaksanaan Asuhan Kebidanan Komprehensif di Praktik Bidan Mandiri Tahun 2018

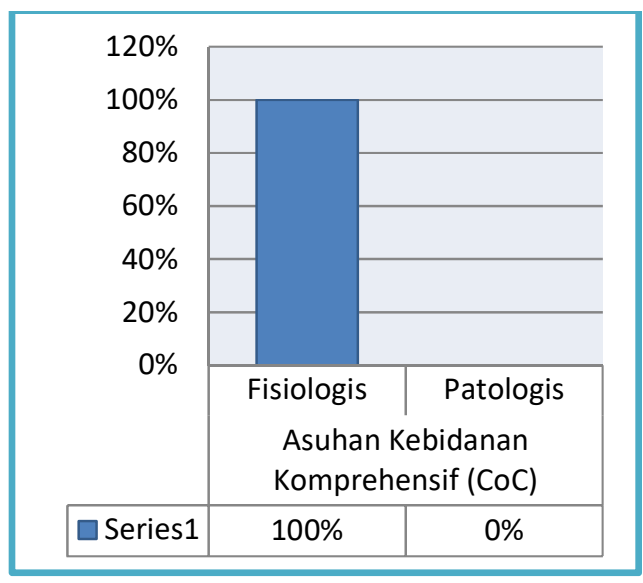

Berdasarkan gambar1diatas, gambaran pelaksanaan asuhan kebidanan komprehensif meliputi kehamilan, persalinan, bayi baru lahir, nifas, neonatus dan asuhan alat konrasepsi di Praktik Bidan Mandiri Samarinda Tahun 2018 yaitu dilakukan secara CoC (Continuity Of Care) semua asuhan mendapatkan hasil fisiologis(100\%).

Asuhan Kebidanan Kehamilan (ANC)

Klien mengalami keluhan pada trimester III, seperti mengeluh sering kencing, rahim yang tumbuh membesar menekan kandung kemihkarena kepala janin mulai turun kebawah pintu atas panggul. Penulis menjelaskan bahwa sering kencing merupakan ketidaknyamanan pada trimester III.Ini adalah hal yang fisiologis, penulis menjelaskan pada ibu bahwa untuk menghindari bangun di malam hari, batasi minum menjelang berangkat tidur.Saat batuk, tertawa, dan bersin, kadang-kadang keluar air kencing sedikit.Untuk menghindari hal ini, lakukan latihan panggul dengan teratur, hindari sembelit dan sering-sering kosongkan kandung kemih. Keluhan yang dirasakan klien selama trimester III sesuai dengan ketidaknyamanan yang akan dirasakan pada saat trimester III sehingga keluhan masih dapat diatasi.

\section{Asuhan Kebidanan Persalinan (INC)}

Terjadi pengeluaran lendir dan darah dikarenakan pendataran dan pembukaan, pembukaan menyebabkan selaput lendir yang terdapat pada kanalis servikalis terlepas, terjadi pengeluaran darah karena kapiler pembuluh darah pecah.Terjadi pengeluaran cairan akibat pecahnya selaput ketuban.Teori ini sesuai dengan klien dimana klien mengalami 
mulesserta terasa kencang, keluar lendir bercampur darah diperiksa pembukaan $4 \mathrm{~cm}$.Lama kala I pada primigravida berlangsung 12 jam dan pada multi gravida berlangsung sekitar \pm 8 jam. Hal ini sesuai dengan klien dimana klien adalahmultigravida, kala I berlangsung \pm 4 jam, yakni pada pukul 13.30 WITA di periksa hasil pembukaan $4 \mathrm{~cm}$ dan pada pukul 15.25 WITA pembukaan $10 \mathrm{~cm}$ dalam hal ini pasien dalam keadaan normal.Kala II adalah kala pengeluaran bayi yang berlangsung \pm 2 jam pada primigravida dan \pm 1 jam pada multigravida. Hal ini sesuai dengan keadaan klien pada pukul 15.25 WITA pembukaan $10 \mathrm{~cm}$, ketuban (-), portio tidak teraba, penurunan kepala hodge IV, ada rasa ingin BAB serta his semakin kuat dan teratur yaitu 4 kali 10 menit dengan durasi 40 - 50 detik. Pada pukul 15.35 WITA bayi lahir spontan dengan jenis kelamin perempuan A/S : 7/9.Kala III adalah waktu untuk pelepasan dan pengeluaran plasenta setelah kala II yang berlangsung tidak lebih dari 30 menit. Penulis melakukan manajemen aktif kala III yang terdiri dari langkah utama pemberian suntik oksitosin dalam 1 menit pertama bayi baru lahir, melakukan peregangan tali pusat terkendali dan massase fundus uteri.Kala III klien berlangsung dengan baik dan normal tanpa adanya penyulit. Lama kala III berlangsung sekitar 15 menit.

Hal ini sesuai dengan teori bahwa kala III berlangsung tidak lebih dari 30 menitKala IV dimulai dari lahirnya plasenta sampai 2 jam pertama post partum.Hasil pemantauan kala IV klien masih dalam batas normal dan tidak ada kesenjangan antara teori dan praktik.

\section{Asuhan Kebidanan Bayi Baru Lahir}

Bayi baru lahir normal adalah berat lahir antara 2500-4000 gram, cukup bulan, lahir langsung menangis dan tidak ada kelainan congenital (cacat bawaan) yang berat. Hal ini sesuai dengan bayi yang lahir dengan berat badan 3800 gram.Pada pukul 15.35 WITA bayi lahir spontan dengan jenis kelaminperempuan dengan nilai APGAR score yaitu A/S : 7/9. Dan penanganan bayi diberikan injeksi Vit K, serta diberikan salep mata.

\section{Asuhan Kebidanan Postnatal Care (PNC)}

Masa nifas dimulai setelah kelahiran plasenta dan berakhir ketika alat-alat kandungan kembali seperti keadaan sebelum hamil.Masa nifas berlangsung selama kira-kira 6 minggu. Kunjungan nifas pertama pada masa 6 jam sampai dengan 3 hari setelah persalinan, kunjungan kedua dalam waktu hari ke 4 sampai dengan hari ke 28 setelah persalinan, dan kunjungan ke 3 dalam waktu hari ke 29 sampai dengan hari ke 42 setelah persalinan.Pemeriksaan yang diberikan yaitu pemeriksaan tekanan darah, nadi, respirasi, suhu, pemeriksaan TFU (infolusi uteri), pemeriksaan lochea dan pengeluaran pervaginam lainnya, pemeriksaan payudara dan anjuran ASI ekslusif 6 bulan, pemberian kapsul vit $A$ 200.000 IU sebanyak 2 kali, pertama segera setelah melahirkan, kedua diberikan setelah 24 jam pemberian kapsul vit A pertama. Dan Pelayanan KB pasca persalinan.

\section{Asuhan Kebidanan pada Neonatus}

Pada kunjungan neonatus I yaitu 12 jam setelah kelahiran penulis melakukan pemantauan, keadaan 
umum neonatus baik, nadi, pernafasan serta suhu tubuh neonatus dalam batas normal.Tali pusat bayi baik, tidak ada tanda-tanda infeksi tali pusat.Neonatus mengkonsumsi ASI dan neonatus telah BAK \pm 4 kali berwarna kuning jernih, BAB 1 kali berwarna kehitaman.Pada kunjungan II 5 hari setelah persalinan, penulis melakukan pemeriksaan pada neonatus, hasilnya keadaan umum baik,nadi, pernafasan serta suhu tubuh neonatus dalam batas normal, eliminasi baik, dan nutrisi terpenuhi. Tali pusat bayi sudah lepas dan bayi dalam keadaan sehat. Dan pada kunjungan III 26 hari setelah kelahiran keadaan masih dalam batas normal, Dari kunjungan I sampai kunjungan II neonatus dalam keadaan baik dan hasil pemeriksaannya pada fontanel minor dan fontanel mayor neonatus masih terbuka. Hal ini sesuai dengan teori yaitu pada fontanel minor tertutup pada usia 8 minggu. Dan fontanel mayor tertutup pada umur 18 bulan (1,5 tahun).

\section{Asuhan Kebidanan Pelayanan Kontrasepsi}

Kontrasepsi berasal dari kata kontra yang berarti mencegah atau melawan, sedangkan konsepsi adalah pertemuan antara sel telur yang matang dan sel sperma yang mengakibatkan kehamilan. Maksud dari kontrasepsi adalah menghindari/ mencegah terjadinya kehamilan sebagai akibat pertemuan antara sel telur yang matang dan sel sperma.Usia klien saat ini adalah 29 tahun. Peneliti melakukan konseling tentang persiapan dalam menggunakan alat kontrasepsi yang akan digunakan setelah berakhirnya masa nifas. Setelah konseling tentang macam-macam alat kontrasepsi, klien memutuskan untuk menggunakan metode suntik 3 bulan.Klien menggunakan metode suntik 3 bulan ini karena sebelum kehamilan ini klien telah menggunakan kb suntik 3 bulan dan merasa cocok dengan metode ini.Keputusan yang telah diambil oleh klien dan suami sesuai dengan keinginan klien. Peneliti beropini, metode kontrasepsi jangka panjang lebih baik digunakan oleh klien karena usia klien yang sudah 29 tahun dan sudah mempunyai 2 anak. Namun klien tidak tertarik dengan kontrasepsi lain selain suntik 3 bulan.

\section{KESIMPULAN}

Pelaksanaan asuhan kebidanan secara komprehensif (Continuity Of Care) di Praktik Bidan Mandiri yang terstandarisasi APN (Asuhan Persalinan Normal) Samarinda Tahun 2018, berjalan dengan fisiologis meliputiasuhan kehamilan, bersalin, bayi baru lahir, nifas, neonatus, hingga pelayanan kontrasepsi, dapat ditarik kesimpulan bahwa pentingnya asuhan yang diberikan olehbidan terhadap ibu pada masa kehamilan hingga pelayanan kontrasepsi setelah melahirkan sebagai deteksi dini adanya komplikasi yang mungkin terjadi dapat dihindari atau ditanggulangi.

\section{DAFTAR PUSTAKA}

Ambarwati, E. R., \&Diah, W. (2010). Asuhan Kebidanan Nifas. Yogyakarta: Nuha Medika

Arum, D. N.,\& Sujiyatin, (2011). Panduan Lengkap Pelayanan KB Terkini. Jogjakarta : Muha Medika 
Manuaba, Ida Bagus Gde, (2010). IImu Kebidanan, Penyakit Kandungan \& Keluarga Berencana Untuk Pendidikan Bidan. Jakarta: EGC

Kustiati,S, (2017). Determinan Faktor yang Berhubungan dengan Kinerja Bidan Dalam Program Perencanan Persalinan dengan Pencegahan (P4K). Gaster : Jurnal IImu Kesehatan Jilid 15 Terbitan 1 hal 7 17.

Kustiati,S.,\& Maimunah, E. (2018). Asuhan Kebidanan Komprehensif pada Ny. S di Puskesmas Sibela Mojosongo. Gaster : Jurnal IImu Kesehatan.

Marmi, (2016). Intranatal Care. Yogyakarta: Pustaka Pelajar

Noorbaya, S (2018). Komunikasi Kesehatan. Yogyakarta : Gosyen Publishing

Noorbaya, S (2016). Faktor-Faktor Yang Berhubungan Dengan Kejadian Komplikasi Persalinan Di Rs. Am.Parikesit Tenggarong: Jurnal Kebidanan Mutiara Mahakam. Hal 41-50.

Sukarni, I, K., \& Margarwth Z. H., (2013). Kehamilan, Persalinan dan Nifas dilengkapi dengan Patologi. Yogyakarta : Nuha Medika 